\title{
TA IÑ FIJKE XIPA RAKIZUAMELUWÜN Historia colonialismo y resistencia desde el país mapuche, de Enrique Antileo y otros autores
}

(Stgo.: Ediciones comunidad de historia mapuche, 2012)

Raquel Olea

\section{Desde el despojo. Un agencia- miento colectivo de la historia}

Los 14 autores que participan de la factura del libro se sitúan - para pensar y decir lo que proponen- en el lugar de su propia y particular identidad, en su diferencia étnica social y cultural. Con un sentido de conciencia y orgullo nacional, los autores enfrentan la re-visión a la historia que los ha oprimido. Este gesto de escritura se patentiza en las referencias bilingües que nos recuerda la presencia de la lengua mapuche en el español que hablamos, en el modo de nombrarse de los autores, quienes no solo se identifican con el nombre del padre, sino también realzando la línea materna, como es, seguramente la tradición familiar en la constitución de la identidad; en las múltiples referencias a su diferencia y particularmente en el sentido crítico y cuestionador del absoluto con que el pensamiento chileno los ha hablado, ha hablado su historia y ha demarcado las fronteras geopolíticas y culturales que los ha situado en el lugar de "la otredad" interiorizada ;por ello la preposición desde que marca el titulo como punto de habla, hace de cada uno de estos textos una producción políticamente situada que señaliza un territorio particular de lengua y de política cultural; el gesto apela al lector a realizar una lectura que abra en los textos la productividad de aquello no dicho antes, no escrito en la historiografía oficial

A mi juicio, este libro enfatiza con sus aportes y reflexiones el momento fundacional actual en lo que significa la constitución de un nuevo discurso mapuche 
en Chile. No quiero decir con esto que antes no hayan habido producción discursiva y textual importante desde voces mapuche, pero este libro instala la legitimidad de un corpus que elabora una discursividad históriopolítica que interviene espacios de pensamiento disciplinario, social y político al abrir otra lectura de la historia y del presente. En ese sentido este libro inicia una nueva potencia del pensamiento para leer otros textos que vendrán desde las coordenadas aquí iniciadas. Quiero decir que este libro construye un recorrido que fisura los discursos oficiales con un conocimiento inédito, el de la palabra y el saber de lo mapuche como sujeto de su propia historia.

Saber legitimado por la voz de su particular subjetividad cultural constituida por la trayectoria de una lucha que hace posible la conceptualización de la experiencia. Este libro despliega la voz histórica que habla desde su situación de oprimido. Este que es el gesto político y cultural fundamental de estos textos, el de la producción del sujeto mapuche como agente de discurso público y político recusa el lugar "del otro" como objeto de la mirada y de la palabra del historiador, del antropólogo, o de otras palabras de supuesto saber disciplinario que lo han hablado desde lugares interesados en la perpetuación de un etnocentrismo que oculta la activa participación de agenciamiento mapuche, tanto en las negociaciones coloniales como en las posteriores disputas con el Estado de Chile. Y esto aún y a pesar de sus derrotas.

La construcción de la historia desde la propia palabra, el discurso de la experiencia y el saber de la historia de un pueblo aparentemente recluido en la calidad de objeto del saber del dominador se ve aquí fuertemente puesta en cuestión por cuanto radicaliza la mirada y la perspectiva del relato; las fronteras discursivas de los saberes oficiales situados en lo inamovible quedan así bajo sospecha.

Iniciando un recorrido de la historia desde la época colonial, en una perspectiva que refrenda la condición de la nación mapuche, "resulta imprescindible -como señala José Millalen Paillal- hacer referencia a la celebración de los Parlamentos entre la corona española y la sociedad mapuche: "Estas instancias constituyeron espacios políticos bilaterales entre ambos entes colectivos soberanos, los que al compartir una frontera territorial crearon mecanismos a través 
del cual debieron regular su convivencia y ratificar en el tiempo soberanía y alianza. Mirado desde hoy, estos parlamentos y sobre todo sus acuerdos constituyen antecedentes históricos fundamentales para entender al sujeto colectivo mapuche que se ha autoafirmado como tal y en la misma medida ha demandado el ejercicio de derechos que le asiste, no obstante transitar por procesos distintos desde el momento del surgimiento de los Estados". La referencia es clara, y permite interrogar en ella al Estado de Chile, ¿Qué sucedió posteriormente a la independencia? ¿Qué razones de Estado impidieron la continuidad del respeto a esos acuerdos y a esa frontera compartida? ¿ Con qué sentido y desde qué posición el Estado chileno naciente, desechó y borró aquella historia anterior? Los argumentos para zanjar esta disputa -así lo dicen estos textos- están inscritos en la arcaica concepción civilizatoria ilustrada que denegó el carácter de civilización a aquello que no conocía, aspecto fundamental en la constitución de las naciones latinoamericanas, conducente a la exclusión y mutilación de las lenguas, los cuerpos y los conocimientos propios del continente, favoreciendo con ello la adscripción eurocéntrica que caracteriza hasta hoy a las elites gobernantes.

Es así como comprender, desde esta nueva perspectiva, la historia de la nación mapuche nos lleva a reconocer en esas decisiones múltiples aspectos vigentes de nuestra dependencia cultural de los discursos falologocéntricos que han regido lo latinoamericanos dominante.

Situados con rigor en los conceptos más productivos e interesantes de los estudios de la subalternidad y los estudios poscoloniales, los textos aquí reunidos legitiman su lugar de habla en los intersticios de las certezas con que se ha construido el pensamiento occidental, en los entremedios de los binarismos con que los discursos de la razón occidental han devaluado formas de alteridad ajenas a sus paradigmas.

Los textos aquí conjugados realizan una radical fisura a los discursos dominantes que en su voluntad hegemónica han desechado los potenciales de aquello que la crítica literaria, La crítica canadiense-norteamericana Marie Louise Pratt nombró como "zona de contacto", la producción de saberes surgidos de la interacción fronteriza y el tránsito de cuerpos, discursos 
y conocimientos propios de las zonas que vinculan culturas de distintas procedencias.

En el contexto de estas coordenadas queda en evidencia la imposibilidad de la borradura junto a la potencia de una verdad oculta, el sujeto mapuche ha estado siempre presente y ha tenido una intervención constante en su propia historia como sujeto de lucha y de resistencia, -como "comunidad imaginada" diría B. Anderson-. Constituyendo una singularidad identificable es a pesar de sus pérdidas históricas una nación viva que hoy vuelve a retomar su propia voz y lengua para cuestionar tanto los discursos que la han hablado, como a las formas en que las políticas de integración neutralizan y desvían la legitimidad de sus demandas.

La referencia y revisión de la historia tiene la función de situar el presente en un continuum colonial de dominación con el que se analizan situaciones que desde los comienzos de la República hasta la actualidad, permite a los autores construir una perspectiva de sujeto despojado, tanto del territorio, como de su lengua, su ética, sus costumbres. En este contexto Enrique Antileo Baeza se apropia de la noción de diáspora para trabajar la in- migración a las ciudades que se vienen operando durante todo el siglo $\mathrm{XX}$. La diáspora como concepto histórico viene a destituir y a de-construir la distinción urbano-rural con que los discursos dominantes han reducido en lo demográfico las múltiples afecciones experienciadas por los sujetos mapuche "en tanto protagonistas de procesos que implican a la etnicidad, la clase y/o el género en sus desplazamientos territoriales".

Otorgándole a la noción de multiculturalismo el rango de "una nueva modalidad de política colonialista, en el marco del neoliberalismo. El texto enuncia, "Las realidades de la diáspora requieren de un concepto de nación que sea capaz de incluir las dispersas situaciones en las que se encuentran la población mapuche". La propuesta de Antileo Baeza busca entregar elementos para descolonizar las formas de mirar el presente mapuche.

Los textos referidos al presente destacan la necesidad de configurar esa realidad dispersa e invisibilizada, apelan a pensarla destacando las formas de asociación generadas en las ciudades, como lo hace el texto de Felipe Curivil Bravo, al nombrar las formas de injusticia y nomadía que se viven en las relaciones la- 
borales, las acciones y lenguajes contestatarios que se desarrollan frente a las políticas públicas de integración que operan como formas de negación de lo propio mientras mayoritariamente obligan a la asimilación y la desidentidad. Iluminador es en este sentido el texto "Construcción sociopolítica de la ley lafkenche " que escribe Susana Huenul Colicoy; referido a la Ley General de Pesca y Acuicultura de 1991, la autora se centra en mostrar el poder de las acciones colectivas como factor generador de cambios en la configuración de las relaciones con el Estado chileno.

En esta misma línea el artículo de Andrés Cuyul Soto realiza un análisis crítico referido a la patrimonialización de la salud mapuche. Utilizando la noción de etnofagia como práctica domesticadora, el autor revisa el Programa Nacional de Salud y Pueblos Indígenas del Estado de Chile para concluir que este reproduce un discurso culturalista esencialista e ideal de lo mapuche que le permite intervenir en las comunidades de manera reducida y asistencialista para desde sus intereses definir un supuesto bienestar de las personas mapuche, pero sin antes hacer un verdadero diagnóstico de las determinaciones estructura- les, históricas y socioculturales que influyen en la salud de las comunidades. Esto es leído por el autor como una naturalización de su condición de ciudadanos de segunda categoría.

Por su parte refiriéndose a la producción literaria Maribel Mora Curialao reafirma la misma posición, refiriéndose a la producción literaria. La autora toma como punto de partida el año 1989 en que el poeta Lionel Lienlaf publicó el texto poético bilingüe Mapudungun/español Se ha despertado el ave de mi corazón. A través de una exhaustiva y bien documentada revisión de la inscripción y legitimidad de una importante producción poética en una escena literaria que unilateralmente construida ha desconocido particularidades geopolíticas de la nación mapuche (lo mapuche-chileno, lo mapuche argentino la autora hace referencias a las afecciones y limitaciones que ha padecido la obra por las condiciones de producción de la escritura y de sus autores. La literatura mapuche, dice, surge desde los márgenes de las sociedades en que se inserta. Los modos como la autora interroga los mecanismos de integración/exclusión de la literatura mapuche, aportan claves de revisión del mapa y las fron- 
teras de la literatura chilena. Su reflexión deja planteada. Entre otras, una interesante pregunta ¿Cómo leer estas escrituras?

Aunque no refiero en esta reseña la totalidad de los textos que constituyen este libro fundamental, destaco el particular interés inscrito en el desarrollo del discurso crítico que este corpus de textos produce como recorrido histórico cultural de una nación oprimida. Los autores elaboran productivos análisiscrítico-políticos, en un lenguaje duro, políticamente informado y rigurosamente sustentado en conceptos propios del pensamiento contemporáneos afirmando una voluntad declarada de producir agenciamientos real y simbólico como sujetos de saber /poder en lo que refiere a su historia pasada y a su realidad presente. Esto los sitúa, tanto frente a los supuestos saberes disciplinarios como a los poderes institucionales en calidad de interlocutores válidos que articulan políticas referidas a lo propio, demarcando su identidad y posicionamiento, como comunidad situada frente a otra -la chilena- con la que convive pero que no es la misma .
La discursividad así desarrollada construye una utopía de mundo y de futuro.

El corpus abre el conocimiento al reconocimiento de un discurso fuerte de diferencia y alteridad legítima, su textualidad provoca un deseo de saber y de interlocución mayor con todas las dimensiones de lo real que refiere, porque su lectura sitúa a quien lee en ese no saber de algo que estando muy cerca ha permanecido ausente, algo de lo que hemos sido privados por los efectos de las políticas de constitución de una Nación-Estado que no miró ni intereses ni bienes internos de quienes habitarían en ella sino que se fundó en una mirada y un deseo hacia lo exterior, asimilándose a lo blanco y europeo. La producción de una identidad mentida frente a los límites de negociaciones realizadas por una elite excluyente, dejó en un afuera de su frontera real y simbólica los discursos que no participaron de sus ideologías, sus alianzas políticoreligiosas y sus estrategias. Pues bien, esa frontera, en sus más amplias dimensiones, cae bajo sospecha con la lectura de estos textos. 